\title{
Acceleration of Load Changes by Controlling the Operating Parameters in CFB Co-Combustion
}

\author{
Jens Peters*, Eric Langner, Jochen Ströhle and Bernd Epple \\ Institute for Energy Systems and Technology, Technical University of Darmstadt, Darmstadt, Germany
}

OPEN ACCESS

Edited by:

Kalpit V. Shah,

RMIT University, Australia

Reviewed by:

Ahmet Arisoy,

Istanbul Technical University, Turkey Fehmi Akgun,

TUBITAK Marmara Research Center

Energy Institute, Turkey

David Pallarès,

Chalmers University of Technology,

Sweden

*Correspondence:

Jens Peters

jens.peters@est.tu-darmstadt.de

Specialty section:

This article was submitted to Advanced Clean Fuel Technologies,

a section of the journal

Frontiers in Energy Research

Received: 08 March 2021

Accepted: 06 May 2021

Published: 31 May 2021

Citation:

Peters J, Langner E, Ströhle J and Epple B (2021) Acceleration of Load Changes by Controlling the Operating Parameters in CFB Co-Combustion.

Front. Energy Res. 9:677950.

doi: 10.3389/fenrg.2021.677950
The integration of intermittent renewable energy sources into the electricity market requires flexible and efficient technologies that compensate for the fluctuating electricity demand. A circulating fluidized bed (CFB) boiler is a suitable solution due to its fuel flexibility, but the thermal inertia of the fluidized bed can have negative effects on the load following capabilities. This study investigates the influence of the operating parameters of the fire side on the speed of load changes on the waterside. Co-combustion of lignite, straw, and refuse derived fuel (RDF) was carried out. In a $1 \mathrm{MW}_{\text {th }}$ pilot CFB combustor fifteen load changes were performed with a varying step input of the primary air, the secondary air, and the fuel mass flow. The step input of the primary air had a large influence on the load ramps, as it strongly affects the solids concentration in the upper furnace. The step size of the fuel mass flow had a positive effect on the load change rate. Based on the results, concepts were developed to accelerate load ramping by controlling the hydrodynamic conditions and the temperature on the fireside.

Keywords: transient operation, load changes, renewable energy, Co-combustion, circulating fluidized bed combustion, flexibility

\section{INTRODUCTION}

The usage of renewable energy sources in the energy sector is necessary to mitigate climate change (Edenhofer et al., 2011). Fluctuating energy sources such as solar and wind play a decisive role in this context. The worldwide installed capacity of power from wind and photovoltaics increased from $183 \mathrm{GW}_{\mathrm{el}}$ in 2009 (Paraschiv et al., 2014) to $1,096 \mathrm{GW}_{\mathrm{el}}$ in 2018 (Renewables, 2019). These technologies have in common that they are not suitable for baseload operation due to their fluctuating electricity supply (Paraschiv et al., 2014). One way to integrate these intermittent energy sources into the energy market is to use conventional technologies that can provide electrical energy on demand. The demand for the ability of these technologies to perform faster load cycling operations will increase as the development of fluctuating energy sources progresses. Faster load changes become necessary and the minimum load of the technologies must be reduced. At the same time, the $\mathrm{CO}_{2}$ emissions of these processes should be as low as possible, i.e., they require

\footnotetext{
Abbreviations: Latin symbols; A, surface area $\left[\mathrm{m}^{2}\right] ; c_{P}$, specific heat capacity $[\mathrm{kJ} / \mathrm{kg} / \mathrm{K}] ; \mathrm{N}$, standard conditions $\left(0^{\circ} \mathrm{C}\right.$, 1.01325 bar); $Q$; $T$, temperature $\left[{ }^{\circ} \mathrm{C}\right] ; \mathrm{t}$, Time; $\dot{V}$, volume flow rate $\left[\mathrm{Nm}^{3} / \mathrm{h}\right]$; Greek symbols; $\alpha$, heat transfer coefficient [W/ $\left.\left(\mathrm{m}^{2} \mathrm{~K}\right)\right] ; \rho$, density $\left[\mathrm{kg} / \mathrm{m}^{3}\right] ; \tau$, characteristic time constant; Subscripts; CL, cooling lances; el, electrical; furn, furnace; l, liquid; th, thermal; Q, a.r., as received; CFB, circulating fluidized bed; FTIR, Fourier-transform infrared spectroscopy; ID, induced draft; MCR, maximum continuous rating; n.a., not analyzed; NDIR, nondispersive infrared sensor; PC, pulverized coal; RDF, refuse derived fuel.
} 
high efficiency and they should be able to utilize fuels from renewable sources such as biomass and waste-derived fuels. Carbon capture processes such as chemical looping (Ströhle et al., 2014; Ströhle et al., 2015; Ohlemüller et al., 2017; Ohlemüller et al., 2018), calcium looping (Helbig et al., 2017; Hilz et al., 2019; Haaf et al., 2020; Ströhle et al., 2020), or integrated gasification combined cycle (Descamps et al., 2008; Cormos, 2012; Heinze et al., 2018; Heinze et al., 2019) can be used for this purpose, but retrofitting power plants or building new plants is costly and time-consuming.

CFB combustion of solid fuels can be a cost-effective and rapidly applicable option for this particular task. It is a highly efficient technology (Grace et al., 1997; Oka, 2003; Lockwood, 2013) and is suitable to combust solid fuels with very different mechanical, physical, and chemical properties (Walter and Epple, 2017; Peters et al., 2020). It can be used both on a small scale (Yates and Lettieri, 2016) for decentralized solutions and on a centralized level with an electrical power of up to $600 \mathrm{MW}_{\mathrm{el}}$ (Jäntti et al., 2012; Lyu et al., 2019). CFB co-combustion of several fuels can reduce operating costs by responding to regional and seasonal fuel availability and has a large potential for $\mathrm{CO}_{2}$ emission reduction at low costs (Sami et al., 2001; Hansson et al., 2009; Werther, 2009; Al-Mansour and Zuwala, 2010). The most common approach for co-combustion is direct cocombustion (Al-Mansour and Zuwala, 2010; Basu et al., 2011), where the fuels are combusted in the same furnace, which causes low capital costs for retrofitting existing power plants.

The high fuel flexibility is made possible by a large proportion of inert particles in the fluidized bed, e.g., sand and ash. However, the high thermal inertia of this material slows down the load following capabilities of the plant (Lockwood, 2013). Modern CFB boilers are reported to have maximum load following capabilities of $4-7 \% \mathrm{MCR} / \mathrm{min}$ (maximum continuous rating per minute) (Mills, 2011; Lockwood, 2013), which is comparable to pulverized coal (PC) boilers. The start-up and shut down times are longer than for comparable PC boilers (Mills, 2011; Lockwood, 2013). Novel approaches must be developed to keep up with the constantly growing demand for faster load change rates. It has been found that the thermal inertia of the furnace refractory walls has a large impact on the transient behavior of the furnace (Park and Basu, 1997; Peters et al., 2020). When modeling a CFB combustor, the heat capacity and the thermal conductivity of the bed material must be modeled correctly to reflect the dynamic behavior (Zheng et al., 1997; Alobaid et al., 2020). This implies that the bed material is of great importance during load following operation. Concepts with thermal energy storage units were developed to utilize the storage capacity of the bed during load changes (Arias, 2016; Stefanitsis et al., 2020). Control strategies for the waterside were proposed to improve the transient operation of a CFB boiler (Henderson, 2014). Majanne et al. (Majanne et al., 2017) suggested using the energy storage capacity of the drum boiler to produce extra steam by a sudden decrease of the drum pressure. Beiron et al. (Beiron et al., 2019) investigated the settling times on the waterside in dependence of changes of the boundary conditions (e.g., heat input to the waterside) by numerical simulation. The carbon inventory inside the bed has a major impact on the load following capabilities of a CFB boiler, as it damps any changes in the fuel feeding rate. Gao et al. (Gao et al., 2017) and Tourunen et al. (Tourunen et al., 2003) proposed to take into account this carbon inventory as an energy storage to accelerate the boiler response time by a suitable control strategy, e.g., burning the carbon with additional primary air. The carbon inside the bed depends on the combustion conditions and can be adjusted e.g., by co-combustion of coal and biomass (high volatile content). Liu et al. (Liu et al., 2019) successfully tested the concept of adding pulverized coal to the CFB furnace during a load increase to accelerate the response time of the cold side.

Many studies investigate the behavior of the furnace during transient operation but do not examine how the operating parameters of the fireside determine the speed of the load change at the waterside. There is no study focusing on the impact of e.g., the fuel mass flow, the combustion air, or the fuel type on the load ramps. This study aims to fill this gap of knowledge by presenting CFB co-combustion experiments in pilot scale. The focus is on the heat transfer to the waterside in the furnace during dynamic operation and it is examined which operating parameters have the greatest effect on the transition phase between two steady-state conditions. Fifteen load changes with three different fuel mixtures were carried out with changing step inputs for the fuel mass flow, the primary air, and the secondary air. It is shown that the load changes can be accelerated by controlling the hydrodynamic conditions and the temperature inside the furnace.

\section{EXPERIMENTAL}

\section{Experimental Setup}

Figure 1 shows a flow diagram of the experimental setup. The CFB furnace has an inner diameter of $590 \mathrm{~mm}$ and a reactor height of $8.6 \mathrm{~m}$. The insulating refractory of the furnace was designed according to industrial standards with a thickness of $355 \mathrm{~mm}$. The reactor contains cooling lances, which can be inserted from the top. The immersion depth of these lances can be varied to keep the furnace temperatures in a suitable range for CFB combustion at thermal loads of up to $1 \mathrm{MW}_{\text {th }}$. Solid particles are recirculated to the bottom of the furnace by a cyclone, a standpipe, and a loop seal. The combustion air was supplied at four positions. The electrically preheated primary air was injected via 30 nozzles through the nozzle grid to maintain homogeneous fluidization over the cross-sectional area. Air streamed through the start-up burner during the tests for cooling purposes and to prevent the backflow of particles into the burner unit. At the elevation of $2.74 \mathrm{~m}$ above the nozzle grid, the first secondary air injection was located. Additional secondary air was injected at $6.0 \mathrm{~m}$ height. Bed material was regularly extracted through the bottom of the furnace by a screw conveyor. Solid samples were taken regularly for analysis from the bottom ash, the circulating ash, and the fly ash.

The flue gas and fly ash left the reactor through the cyclone and streamed to the flue gas path. After the cyclone, the content of the main gas components was detected with an NDIR (nondispersive infrared) sensor $\left(\mathrm{CO}_{2}, \mathrm{CO}, \mathrm{NO}\right.$, and $\left.\mathrm{SO}_{2}\right)$ and 


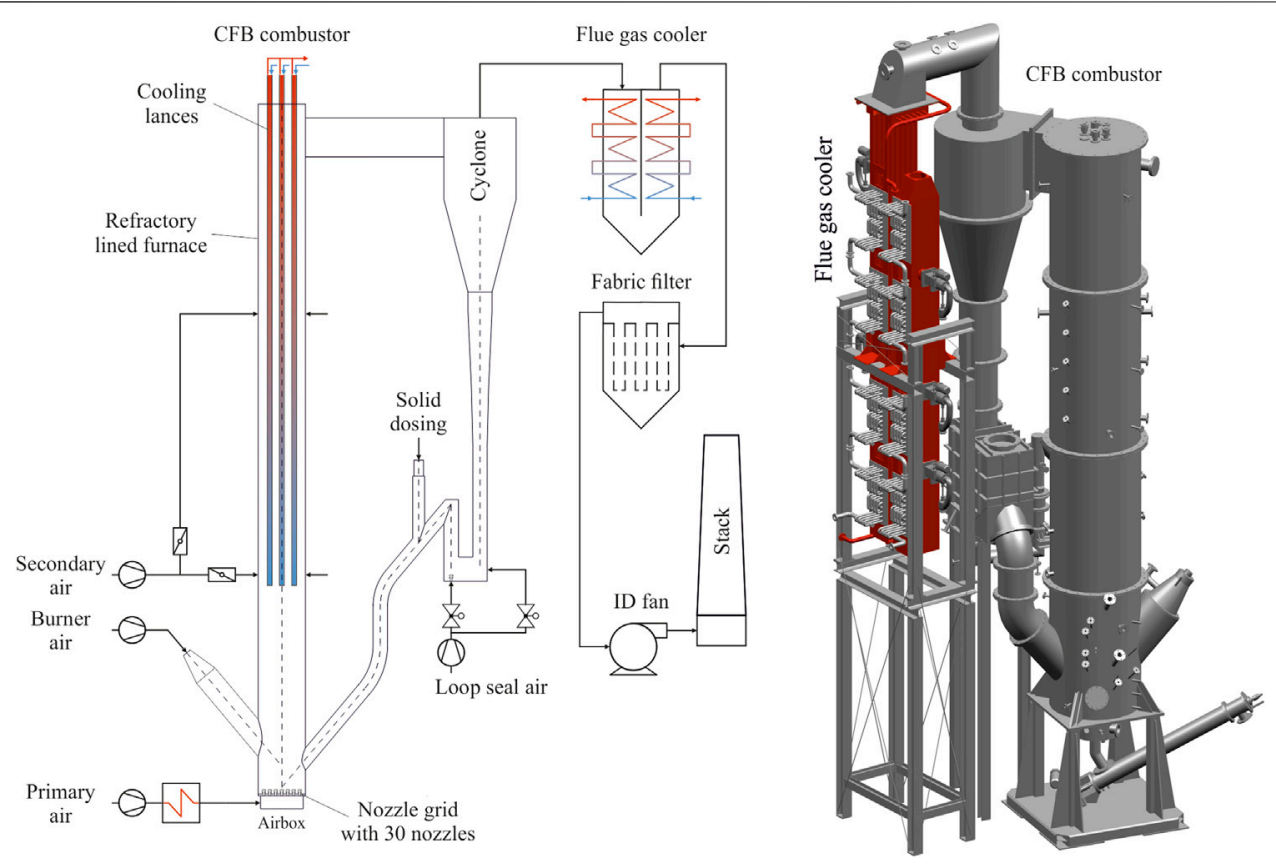

FIGURE 1 | Experimental setup-flow scheme of circulating fluidized bed combustor and periphery.

TABLE 1 | Measurement devices of the CFB pilot plant.

Variable

Temperature

Pressure

Volume flow rate

Gas composition

Mass flow
Location

In riser at height of [m]: $0.25,1.12,1.55,2.38,5.27,6.25,8.21 ; 2 x$ loop seal, $2 x$ standpipe, cyclone outlet In riser at height of [m]: 0.11, 0.22, 0.4, 0.58, 0.91, 1.10, 2.07, 3.42, 7.31, 8.03; 2x loop seal, 2x standpipe, cyclone outlet Combustion air lines, flue gas duct after flue gas cooler

NDIR and paramagnetic after cyclone, FIIR before and after fabric filter

Solid feeding systems for lignite, RDF, straw-pellets, sand a paramagnetic sensor $\left(\mathrm{O}_{2}\right)$. Then, the gas was cooled in a twopath tube bundle and membrane wall heat exchanger unit. The flow rate of the flue gas was measured by a venturi. It entered the fabric filter at approximately $170{ }^{\circ} \mathrm{C}$ to separate the fly ash from the gas. FTIR units (Fourier-transform infrared spectroscopy) were installed before and after the filter to measure the main gas components $\left(\mathrm{CO}_{2}, \mathrm{O}_{2}, \mathrm{H}_{2} \mathrm{O}\right)$ as well as some minor species in the flue gas (e.g., $\mathrm{CO}, \mathrm{SO}_{2}, \mathrm{NO}_{\mathrm{x}}$, and $\mathrm{HCl}$ ). The clean flue gas left the system to the atmosphere by an induced-draft fan and a stack. The ID fan maintained a constant pressure after the cyclone of around -1 mbar.

The solid fuels and sand entered the reactor via the return leg that connects the loop seal and the riser of the furnace. Three different fuel feeding systems were used for the fuels: crushed lignite, pelletized straw, and RDF fluff. The lignite was fed by a screw conveying system capable of transporting fuels with a size of up to $30 \mathrm{~mm}$ with a large volumetric flow rate. The straw pellet feeder was equipped with a twin-screw conveyor, which was able to dose difficult fibrous material due to its self-cleaning ability. The physical properties of RDF fluff were very inhomogeneous and it had a very low volumetric heating value. The RDF was fed by a speed-controlled conveyor belt, which was capable of dosing high volume flows of the fuel with strongly fluctuating physical/ mechanical properties. All solid feeding systems were weighed to determine the mass flow by calculating the mass loss over time.

The temperatures, the pressures, the mass flow rates, and the gas composition were measured continuously inside the furnace, the peripheral systems and the flue gas path, to monitor the experiment. The relevant measurement devices and their location in the plant are listed in Table $\mathbf{1}$.

The flow scheme of the cooling system is shown in Figure 2. Relevant design parameters are presented in Table 2 . The flue gas and particles were cooled inside the furnace by cooling lances. In the experiments, three of five cooling lances were immersed into the reactor at a depth of $6.0 \mathrm{~m}$ each. The mass flow of cooling liquid through the cooling lances and the flue gas cooler as well as the inlet temperatures of the cooling system was kept constant. The mass flow rate of liquid through the lances was measured twice before and after the cooling lances. The temperature of the cooling lances sub-system was measured several times: before the lances, at the 




FIGURE 2 | Flow scheme of the cooling system.

TABLE 2 | Properties of the cooling lances and cooling liquid.

Property

Unit

$-\quad 3$

Number of cooling lances used in the experiment Immersion depth of cooling lances in the experiment Cooling lances surface in contact with the hot side Inner pipe (downflow): Outer diameter/wall thickness Outer pipe (upflow): Outer diameter/wall thickness Inlet temperature of the cooling liquid

Pressure of the cooling liquid

Volume fraction of $\mathrm{H}_{2} \mathrm{O}$ in the cooling liquid

Volume fraction of Antifrogen $\mathrm{L}$ in the cooling liquid

Density of the cooling liquid at $115^{\circ} \mathrm{C}$

Heat capacity of the cooling liquid at $115^{\circ} \mathrm{C}$

$\begin{array}{cl}- & 3 \\ \mathrm{~m} & 6 \mathrm{~m} \\ \mathrm{~m}^{2} & 3.410 \\ \mathrm{~mm} & 42.4 / 4.4 \\ \mathrm{~mm} & 60.3 / 3.6 \\ { }^{\circ} \mathrm{C} & 107-109 \\ \mathrm{bar} & 8-16 \\ \mathrm{Vol} \% & 62 \\ \mathrm{Vol} \% & 38 \\ \mathrm{~kg} / \mathrm{m}^{3} & 964 \\ \mathrm{~kJ} /(\mathrm{kgK}) & 4.01\end{array}$

outlet of each lance, and after the individual streams of the lances were combined again. The cooling liquid streamed downwards through an inner duct of the lances and was preheated thereby. From the bottom of the lances, the cooling liquid streamed upwards in the gap between the inner duct and the outer duct. The outer surface of this duct was in direct contact with the particles and gas inside the furnace. The subject of this publication is the heat transfer to the cooling lances in the furnace during dynamic operation. Therefore, the flue gas cooler is not described in detail here. After leaving the subsystems "cooling lances" and "flue gas cooler", the liquid was cooled to a setpoint of around $110^{\circ} \mathrm{C}$.

\section{Solid Fuels}

The dynamic tests were conducted with three fuel mixtures, namely crushed lignite, a mixture of lignite and straw, and a mixture of lignite and RDF. Fuel samples were taken regularly during the tests and the samples were combined for analysis to have a representative test sample. The origin of the crushed lignite was West Germany. The straw originated from the NorthWestern part of Germany and contained plant residues of e.g., barley, wheat, oats, and rye. The RDF fluff was mainly produced from domestic waste and the main components were plastics, biogenic material (also paper/cardboard), and textiles. The analysis results are shown in Table 3. All fuels had a heating value of $10-15 \mathrm{MJ} / \mathrm{kg}$, while other properties differ strongly. Nearly half of the lignite and RDF consisted of water, while the moisture content of the straw pellets was much lower. RDF and straw have a similar content of volatiles in the dry state of the fuels, which was significantly higher than for lignite. The lignite contained very little ash, while the ash content of straw and RDF were in an expectable range. The three fuels differed strongly in their size, shape, and density, which can potentially complicate the homogeneous fluidization of the fuels. The CFB combustion technology is particularly suitable for the co-combustion of such kinds of fuel mixtures with different properties.

\section{Experimental Procedure}

One target of the experiments was to evaluate the parameters that have the highest influence on the dynamic behavior of the heat transfer inside the furnace during load following operation. Therefore, fifteen load changes were carried out with three different fuel mixtures: lignite, lignite and straw, and lignite and RDF. The series of load changes started for every fuel mixture at a thermal load of $\sim 60 \%$ (with respect to the 
TABLE 3 | Fuel properties (a.r. = as received, n.a. = not analyzed).

\begin{tabular}{|c|c|c|c|c|}
\hline Property & Unit & Crushed lignite & Straw pellets & RDF fluff \\
\hline Lower heating value & $\mathrm{MJ} / \mathrm{kg}$, a.r & 10.8 & 14.6 & 12.3 \\
\hline Moisture & $w t \%$, a.r & 51.2 & 11.4 & 43.1 \\
\hline Volatiles & wt $\%$, dry & 49.7 & 74.4 & 78.3 \\
\hline Fixed C & wt $\%$, dry & 46.2 & 17.4 & 5.40 \\
\hline Ash $\left(815^{\circ} \mathrm{C}\right)$ & wt $\%$, dry & 4.10 & 8.20 & 16.3 \\
\hline Bulk density & $\mathrm{kg} / \mathrm{m}^{3}$ & 716 & 487 & 190 \\
\hline$d(10)$ & $\mathrm{mm}$ & 0.1 & n.a & n.a \\
\hline$d(50)$ & $\mathrm{mm}$ & 2.8 & n.a & 50 \\
\hline$d(90)$ & $\mathrm{mm}$ & 11.9 & n.a & 120 \\
\hline Typical particle length & $\mathrm{mm}$ & n.a & 6.7 & n.a \\
\hline Typical particle diameter & $\mathrm{mm}$ & n.a & 6.1 & n.a \\
\hline
\end{tabular}


FIGURE 3 | Experimental procedure: Load change from 436 to $568 \mathrm{~kW}$ load (lignite and straw co-combustion). (A) Step input (B) Step response.

maximum load: 100\%). After a stabilization time, the load was increased to $\sim 80 \%$. At the beginning of the load step, the overall combustion air (primary and secondary air) was adjusted according to the setpoint of the chosen load (e.g., $80 \%$ combustion air at $80 \%$ load). Simultaneously, the fuel mass flow was continuously adjusted to keep the excess air factor $(\lambda)$ at approximately 1.1. The fuel mass flow fluctuates over time due to its varying properties such as density, particle size, moisture content, or flow characteristics. Therefore, the excess air factor was subject to fluctuations, in particular shortly after adjusting the primary air. With the same procedure, a series of load steps was performed from 80 to $100 \%$, to $80 \%$ to $60 \%$, and to $100 \%$. Exemplary for the three test series Figure 3 illustrates the procedure of the load change from $\sim 60$ to $\sim 80 \%$ load for the cocombustion tests with lignite and straw. Figure 3A shows the setpoint changes for the fuel and air mass flow rates. Figure 3B presents the corresponding response of the bed temperature, the temperature at the reactor top, and the heat transfer to the cooling lances during this load increase. While the heat transfer increases according to the setpoint, the bed temperature decreases from 815 to $765^{\circ} \mathrm{C}$, and the temperature at the top increases from 600 to $650^{\circ} \mathrm{C}$. The bed temperature decreases due to the higher entrainment of bed particles at higher loads. The combustion reactions shift to the freeboard and the cooling of bed particles is more efficient because of increasing contact to the cooling lances and the walls of the furnace in the upper reactor. Peters et al. (Peters et al., 2020) describe in detail the temperature profiles at part load conditions and the corresponding influencing variables.

The share of straw was kept in a range of $21-23 \%$; the percentage is calculated based on the thermal load. The share of RDF in the tests was between 19 and $22 \%$, except for the load change from 60 to $100 \%$ thermal load, where the share was approximately $16 \%$. The pressure sensor directly above the nozzle grid at $0.11 \mathrm{~m}$ was used to control the inventory inside the furnace. Bed material was extracted every time the pressure reached 60 mbar. By this control strategy, the pressure was kept between 50 and 60 mbar. Table 4 shows the boundary conditions of the dynamic tests series with the three fuel mixtures.

\section{Furnace Response to a Step Input}

Exponential decay of a first order system can be used to model the response of a CFB furnace to load steps mathematically. The response can be described with the following equation:

$$
f(t)=\left(f_{0}-f_{1}\right) \cdot e^{-t / \tau}+f_{1}
$$


TABLE 4 | Boundary conditions of dynamic test series with lignite, straw, and RDF.

\begin{tabular}{|c|c|c|c|c|c|c|}
\hline \multicolumn{3}{|c|}{ Share of fuels $\left[\%^{a}\right]$} & \multirow[t]{2}{*}{ Thermal load [kW] } & \multirow[t]{2}{*}{ Excess air factor $[-]$} & \multirow[t]{2}{*}{ Primary air $\left[\mathrm{Nm}^{3} / \mathrm{h}\right]$} & \multirow[t]{2}{*}{ Total combustion air $\left[\mathrm{Nm}^{3} / \mathrm{h}\right]$} \\
\hline Lignite & Straw & RDF & & & & \\
\hline 100 & 0 & 0 & 513 & 1.10 & 500 & 626 \\
\hline 100 & 0 & 0 & 634 & 1.08 & 510 & 752 \\
\hline 100 & 0 & 0 & 788 & 1.11 & 510 & 940 \\
\hline 100 & 0 & 0 & 655 & 1.09 & 510 & 752 \\
\hline 100 & 0 & 0 & 525 & 1.09 & 500 & 623 \\
\hline 100 & 0 & 0 & 766 & 1.09 & 514 & 944 \\
\hline 79 & 21 & 0 & 436 & 1.14 & 422 & 547 \\
\hline 78 & 22 & 0 & 568 & 1.17 & 556 & 712 \\
\hline 77 & 23 & 0 & 691 & 1.16 & 580 & 820 \\
\hline 79 & 21 & 0 & 596 & 1.13 & 556 & 710 \\
\hline 79 & 21 & 0 & 468 & 1.14 & 422 & 543 \\
\hline 78 & 22 & 0 & 718 & 1.10 & 580 & 820 \\
\hline 80 & 0 & 20 & 427 & 1.13 & 392 & 539 \\
\hline 79 & 0 & 21 & 541 & 1.14 & 364 & 656 \\
\hline 81 & 0 & 19 & 684 & 1.12 & 480 & 820 \\
\hline 80 & 0 & 20 & 545 & 1.11 & 364 & 656 \\
\hline 81 & 0 & 19 & 450 & 1.08 & 392 & 526 \\
\hline 84 & 0 & 16 & 703 & 1.09 & 480 & 820 \\
\hline
\end{tabular}

${ }^{a}$ Based on thermal load input of the fuels.


FIGURE 4 | Step input and step response of a first order system with exponential decay. (A) Step input (B) Step response.

$f_{0}$ is the initial value and $f_{1}$ is the final value of the examined variable $f$, e.g., the temperature in the furnace or the heat transfer to the cooling lances. $\tau$ is the characteristic time constant of the first order system. When the time $t$ equals $\tau, 63.2 \%\left(=1-e^{-1}\right)$ of the overall response of the system is done. The time constant $\tau$ is a suitable parameter to describe the response of the CFB furnace to a load step. The time constant can be determined by measuring the time it takes to reach $63.2 \%$ of the final value. Figure 4 exemplarily shows a step response of the heat transfer to the cooling lances to a certain step input (thermal load changes from 80 to $100 \%$ ) with three different time constants.

Often the target during operation is to change the heat transfer to the cooling system as fast as possible to adjust the electrical input/output of the boiler during fluctuating electricity demand.
Therefore, the derivation of the heat transfer over time must be considered. This study focuses on the heat transfer inside the furnace. The characteristic load ramp of the heat transfer to the cooling lances is calculated by dividing the difference in heat transfer between 0 and $63.2 \%$ by the time constant $\tau$ :

$$
\frac{d \dot{Q}_{C L}}{d t}=\frac{\dot{Q}_{C L}(\tau)-\dot{Q}_{C L}(0)}{\tau}
$$

The heat transfer to the cooling lances can be calculated by the enthalpy difference at the cold side of the cooling system, see Eq. 2.3. $\dot{V}_{l}$ is the volume flow rate, $T_{l, \text { in }}$ is the inlet temperature and $T_{l, o u t}$ is the outlet temperature of the cooling liquid. The pressure is constant and the temperature change of the cooling liquid is 


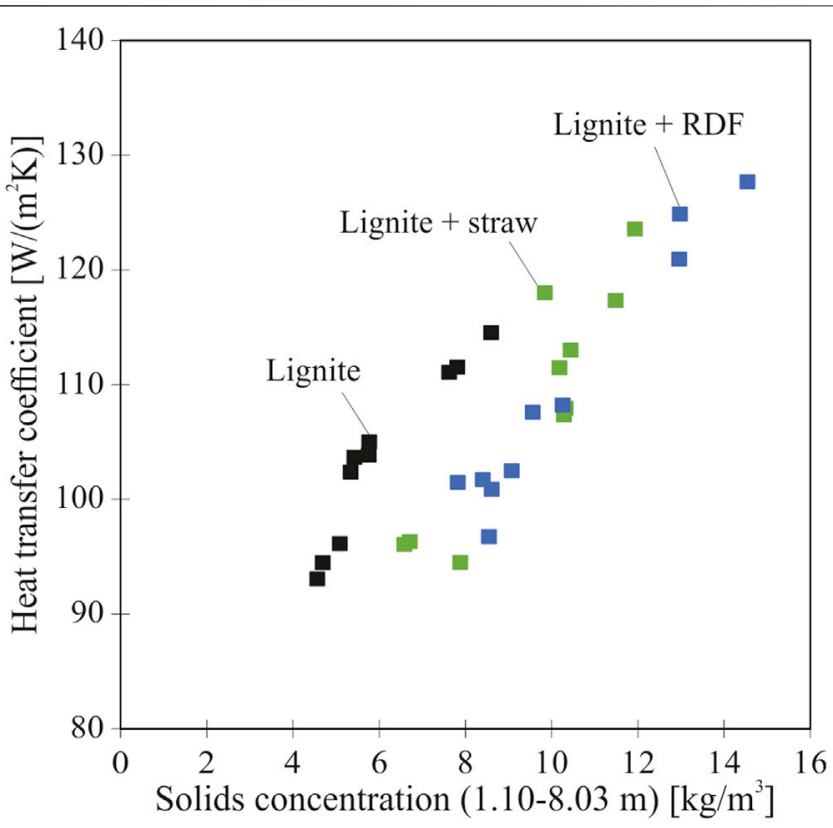

FIGURE 5 | Heat transfer coefficient vs. solids concentration.

moderate, therefore the density $\rho_{l}$ and the heat capacity $c_{p, l}$ of the liquid are assumed to be constant:

$$
\dot{Q}_{C L}=\dot{V}_{l} \cdot \rho_{l} \cdot c_{p, l} \cdot\left(T_{l, \text { in }}-T_{l, o u t}\right)
$$

The heat transfer depends on the temperature difference between the hot and the cold side and on the heat transfer coefficient $\alpha_{C L}$, see Eq. 2.4. The temperature $T_{f u r n, u}$ is the average temperature in the furnace between 1.55 and $8.21 \mathrm{~m}$ height, where the cooling lances are located (Eq. 2.5). This temperature is estimated by the arithmetic mean of the temperature measurements in this area. $T_{l, C L}$ is the average of the inlet and outlet temperature of the cooling liquid (Eq. 2.6). By combining these equations, the heat transfer coefficient can be estimated by Eq. 2.7.

$$
\begin{aligned}
\dot{Q}_{C L} & =\alpha_{C L} \cdot A_{C L} \cdot\left(T_{f u r n, u}-T_{l, C L}\right) \\
T_{f u r n, u} & =\frac{\sum_{i=1}^{n} T_{f u r n, i}}{n} \\
T_{l, C L} & =\frac{T_{l, \text { in }}+T_{l, \text { out }}}{2} \\
\alpha_{C L} & =\frac{\dot{V}_{l} \cdot \rho_{l} \cdot c_{p, l} \cdot\left(T_{l, \text { in }}-T_{l, \text { out }}\right)}{A_{C L} \cdot\left(T_{f u r n, U}-T_{l, C L}\right)}
\end{aligned}
$$

The heat transfer coefficient calculated with Eq. 2.7 is not based on the logarithmic mean temperature difference as usual for heat exchangers. The temperature at the lower end of the tubein-tube cooling lances is not measured, so the logarithmic mean cannot be calculated accurately. Furthermore, combustion reactions take place in the area of the cooling lances, in particular at the secondary air injection point. Therefore, the derivation of the logarithmic mean temperature difference is no longer valid. For these reasons, a simple average temperature



FIGURE 6 | Heat transfer coefficient vs. upper furnace temperature.

difference between the furnace and the water-side was used to calculate the heat transfer coefficient. As this temperature difference is very high at all locations of the heat exchanger surface, the deviance between logarithmic mean temperature difference and the applied calculation method is very small. This approach is considered sufficient to determine the heat transfer coefficient with reasonable accuracy to compare different operating points. Nevertheless, the calculation of the heat transfer coefficient must be considered as a qualitative determination.

It is also mentioned here, that the calculated heat transfer coefficient represents a combination of the heat transfer from the furnace to the tube, the heat conduction inside the tube, and the heat transfer from the tube to the cooling fluid. According to Gnielinski (Gnielinski, 1995), under the given conditions, the heat transfer coefficient from the tube to the liquid can be estimated to $\sim 1920 \mathrm{~W} /\left(\mathrm{m}^{2} \mathrm{~K}\right)$. This is one order of magnitude larger than the overall heat transfer coefficient from the furnace to the fluid, as is shown in Chapter 3.1. Thus, it can be concluded that the heat transfer from the furnace to the tube dominates the overall heat transfer mechanism and an estimation of the heat transfer coefficient using Eq. 2.7 is reasonable to investigate the heat transfer inside a furnace.

The solids concentration in the splash zone and the freeboard has a large influence on the heat transfer to the cooling lances. It is estimated by Eq. 2.8, where $\Delta p_{1.1-8.03 \mathrm{~m}}$ is the pressure difference between 1.1 and $8.03 \mathrm{~m}, g$ is the standard acceleration due to gravity, $A$ is the cross section of the furnace, and $V_{1.1-8.03 ~} \mathrm{~m}$ is the volume of the furnace from 1.1 to $8.03 \mathrm{~m}$.

$$
\left(\frac{m_{\text {solids }}}{V}\right)_{1.1-8.03 \mathrm{~m}}=\triangle p_{1.1-8.03 \mathrm{~m}} \cdot \frac{1}{g} \cdot \frac{A}{V_{1.1-8.03 \mathrm{~m}}}
$$




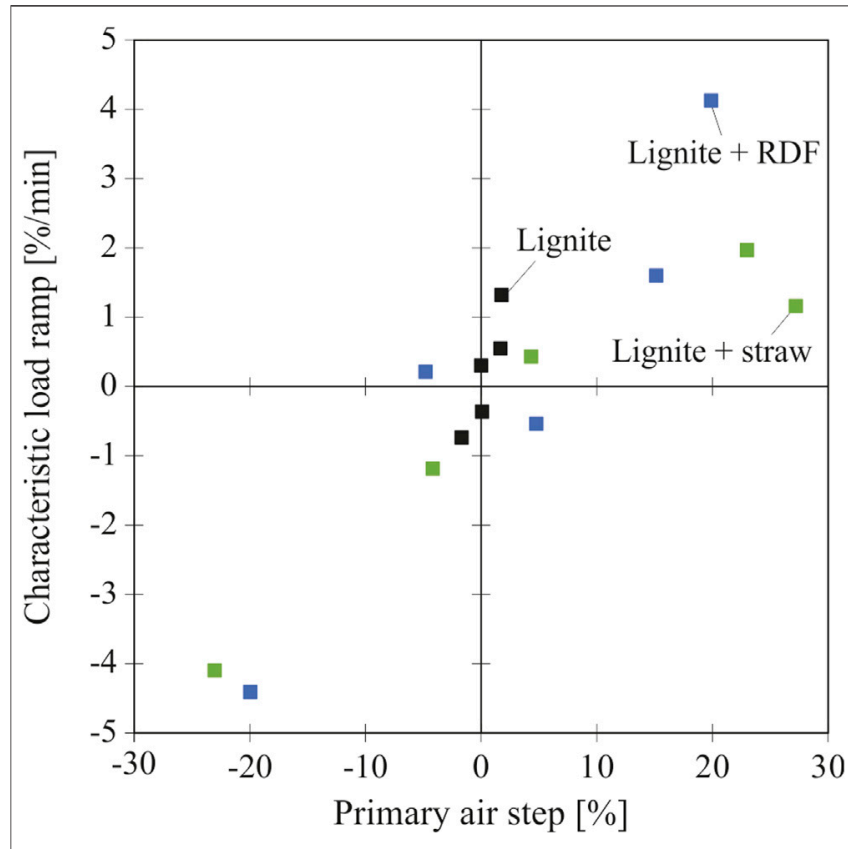

FIGURE 7 | Influence of the primary air step on the characteristic load ramp.

\section{RESULTS AND DISCUSSION}

The transferred heat to the waterside in the furnace directly depends on the heat transfer coefficient $\alpha_{C L}$. In the following, important parameters that determine $\alpha_{C L}$ are presented to provide a basis for further investigations. Afterward, the influence of the primary air, the thermal load, and the excess air factor on the load ramps are assessed. Based on these results, concepts for accelerated load ramps are developed.

\section{Heat Transfer Coefficient}

The time derivative of Eq. 2.4 is shown in Eq. 3.1. It is concluded that load changes are faster when the heat transfer coefficient and the temperature difference between the hot and the cold side changes more rapidly. Therefore, it is important to understand the influence of reactor conditions on the heat transfer coefficient.

$$
\frac{d \dot{Q}_{C L}}{d t}=A_{C L} \cdot\left[\frac{d \alpha_{C L}}{d t} \cdot\left(T_{f u r n, u}-T_{l, C L}\right)+\alpha_{C L} \cdot \frac{d\left(T_{f u r n, u}-T_{l, C L}\right)}{d t}\right]
$$

Figure 5 shows the relation between solids concentration from 1.1 to $8.03 \mathrm{~m}$ (splash zone and freeboard) and the heat transfer coefficient $\alpha_{C L}$. It is shown, that $\alpha_{C L}$ strongly depends on the solids concentration in this area, which is consistent with the findings in literature also for large CFB boilers (Wu et al., 1987; Molerus and Mattmann, 1992; Wirth, 1995; Grace et al., 1997; Molerus and Wirth, 1997; Breitholtz et al., 2001; Oka, 2003; Dutta and Basu, 2004). As the entrainment increases, more particles get in contact with the heat exchanger surfaces. Thereby, particle and gas convection becomes more relevant.

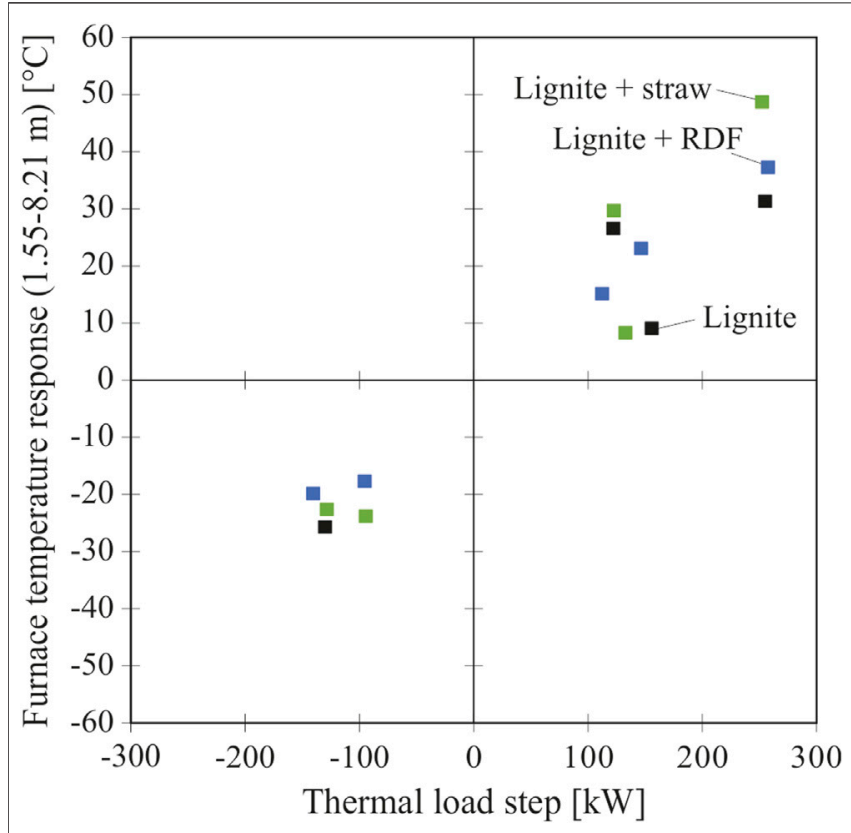

FIGURE 8 | Influence of the thermal load step on the response of the upper furnace temperature.

Besides the solids concentration, it is not obvious from Figure 5 if the type of fuel influences the heat transfer coefficient. The heat transfer coefficient is of higher magnitude in the lignite tests at the same solids concentration. However, the temperature is significantly higher in the lignite tests, which is probably the main factor for the increased $\alpha_{C L}$ in Figure 5. Figure 6 illustrates the temperature dependency of the heat transfer coefficient at similar solids concentrations. The temperature in the upper reactor has a major impact on the heat transfer coefficient. The heat transfer coefficient rises at elevated temperatures due to the increasing influence of the heat transfer by radiation (Biyikli et al., 1987; Grace et al., 1997; Dutta and Basu, 2004; Khavidak et al., 2015). The reason for the different temperature levels is described in another publication, in which the experiments are examined with the focus on the steady-state operation of co-combustion (Peters et al., 2020).

\section{Influence of Primary Air}

The difference of the primary air before and after the load step is called primary air step. Its influence on the load ramp is shown in Figure 7. The primary air step is shown in relative values in percent. Scaling was performed with the maximum primary air flow of all tests, i.e., $580 \mathrm{Nm}^{3} /$ h. The load ramp refers to the heat transfer to the cooling lances in the furnace. In the co-combustion tests, the load changes were faster when the primary air was changed to a greater extent. This was valid for load reductions as well as load increases. For load increases, there is a strong variation of the results, especially for the two straw tests with the highest primary air steps, where the load changes are significantly slower than with RDF at comparable primary air 



FIGURE 9 | Influence of the thermal load step on the characteristic load ramp. (A) Low primary air step (0-15\%) (B) High primary air step (15-30\%).

step changes. These deviations show, that there must be also other important parameters influencing the load ramps. During the lignite tests, mainly the secondary air was changed during the load changes, while the primary air was changed only slightly. Therefore, the primary air variation in the lignite tests was too small to see an influence. However, the load ramps were in a similar corridor for all three fuel mixtures. The primary air strongly influences the entrainment of particles from the bed to the freeboard, which affects the change of the heat transfer coefficient. The entrainment from the bed must be increased rapidly during load increases to accelerate the load change. For load reductions, it is vice versa. Besides the primary air, also other factors have an influence on the entrainment, such as the volatile content of the fuel, the bed temperature, or the size and density of the bed material.

\section{Influence of Thermal Load}

The heat transfer to the cooling lances depends on two parameters: the heat transfer coefficient and the temperature difference between the hot gas side and the cold water side, see Eq. 2.4. It is expected that the thermal load has a large influence on the furnace temperature, therefore the size of the thermal load step should influence the characteristic load ramp.

Figure 8 shows the relation between the thermal load step and the temperature response in the upper furnace. At increasing thermal loads, the average temperature in the upper part of the furnace rises which is due to increasing entrainment of particles causing a more homogeneous temperature profile (Peters et al., 2020). The furnace temperature affects the heat transfer in two ways. There is a direct effect of a larger temperature difference to the cold side. Additionally, the heat transfer coefficient increases with the furnace temperature, as shown in Figure 6. Thus, by controlling the furnace temperature, the load ramps can potentially be accelerated. An increasing temperature should have a positive impact on a load ramp during load increases, while a decreasing temperature should accelerate load reductions.
Figure 9 shows the influence of the thermal load step on the characteristic load ramp of the cooling lances. In Figure 9A, the step changes with low primary steps are presented. There is a trend toward faster load changes when the thermal load experiences a larger load step, which is potentially due to the higher temperature increase, see Figure 8. It does not seem to matter whether the load is reduced or increased. With a similar primary air step and a similar change in the thermal load, the load ramps are of similar order of magnitude. Figure 9B shows the tests with higher primary air steps. The trend toward faster load changes can also be observed, although there is a

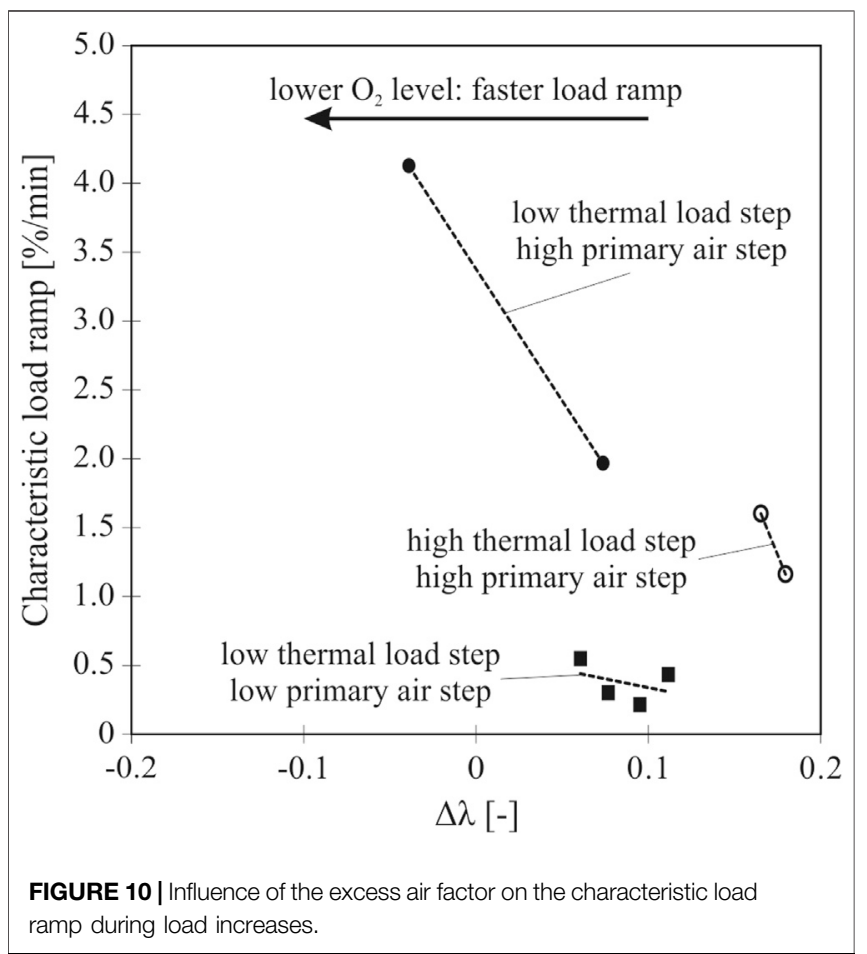


greater variation in the characteristic load ramps for load increasing steps. Therefore, the results indicate that further parameters need to be considered. From both figures it is concluded, that the influence of the thermal load step on the load ramp seems to be less than the influence of the primary air step.

\section{Influence of Excess Air Factor}

Another option to control the temperature in the furnace during load changes is to control the excess air factor $(\lambda)$. During steady-state operation, the excess air factor must be high enough to ensure a high combustion efficiency and low CO emissions. However, when lowering the excess air factor during a load increase, the temperature increase in the furnace should be accelerated. This strategy could be favorable for load increases, while it is vice versa for load reductions. As discussed in Chapter 2.3, the fuel mass flow in the pilot tests is adjusted permanently to keep the excess air factor $(\lambda)$ at approximately 1.1, while the combustion air flow is adjusted only once for every load step. The fuel mass flow fluctuates over time due to its varying properties, which causes variations in $\lambda$, especially after a load step is performed. This typical behavior can be utilized to determine the influence of the excess air factor on the load ramps. To investigate the potential effect, the excess air factor directly after the load change is calculated as an average value between 2 and $5 \mathrm{~min}$ after the load step input. The excess air factor before the load step is then subtracted from this value:

$$
\Delta \lambda=\lambda_{2-5 \text { min after load step }}-\lambda_{\text {before load step }}
$$

Figure 10 shows the influence of $\Delta \lambda$ on the load ramps for load increases. With a low oxygen level after the load step (low $\Delta \lambda$ ), the temperature rises and the load changes should be faster. The fastest load ramp is measured with a low $\Delta \lambda$, which supports the theory of accelerated load ramps by a reduced excess air factor. In the tests with a high thermal load step and a high primary air step, the characteristic load ramps are lower because there is high surplus oxygen directly after the load change, which causes lower temperatures and decelerates the load ramps. The variations in Figure 7; Figure 9 can be explained by the presented results. The results show how important it is to control the fuel mass flow rapidly and accurately, especially during load changes. It becomes apparent that the load change behavior can only be explained by including all three parameters: primary air, thermal load, and excess air factor.

For load reductions, lower temperatures should favor fast load changes. Therefore, there is a potential load ramp acceleration with an increasing $\Delta \lambda$ (more surplus oxygen). Figure 11 shows the results for load reductions. For load changes with a low primary air step, there is a trend toward accelerated load ramps with an elevated $\Delta \lambda$, which supports the theory. For the tests with a high primary air step, the influence of the excess air factor cannot be determined conclusively as the difference between the two test points is too small. More tests are necessary to investigate the effect further and make conclusive and solid statements.

\section{Influence of the Fuel Type}

Figure 7; Figure 9 show no significant influence of the fuel mixture on the load ramps. The load ramps are lower for the lignite tests compared to the co-combustion test, but this is due to the low variation of the primary air in these tests. Figure 5 shows



that the heat transfer coefficient is higher in the lignite tests at the same solids concentration. This is mainly due to the higher temperature in these tests. The entrainment has a significant impact on the heat transfer coefficient. Fuels with high volatile content, such as straw and RDF will potentially cause higher entrainment of particles due to the high amount of gas, which is released in the bed by pyrolysis. It is therefore likely that highvolatile fuels lead to an increased heat transfer coefficient. However, there is no direct impact of the absolute value of the heat transfer coefficient on the load following behavior. A load change is accelerated by a larger time derivative of the heat transfer coefficient and the furnace temperature, see Eq. 3.1. It must be concluded that within the presented range of parameter variation, no influence of the type of fuel on the load ramps is identified.

\section{Concepts for Accelerated Load Ramps}

Based on the knowledge gained, concepts can be developed to accelerate load ramps. Some of these concepts are introduced in this chapter, whereby only the speed of the load change is dealt with and other aspects that may occur (e.g., increased emissions by changing operating conditions: share of the primary air or excess air factor) are not discussed here. Moreover, in the following, the load change concepts are illustrated as step inputs. In large-scale boilers, a smoother ramping of the fuel and the combustion air might be advantageous to have better control over the operating conditions.

The impact of primary air on the load ramp can be utilized by the so-called concept of "boosted hydrodynamics", illustrated in Figure 12. While the fuel mass flow rate increases according to the setpoint of the new load level, the primary air is increased 

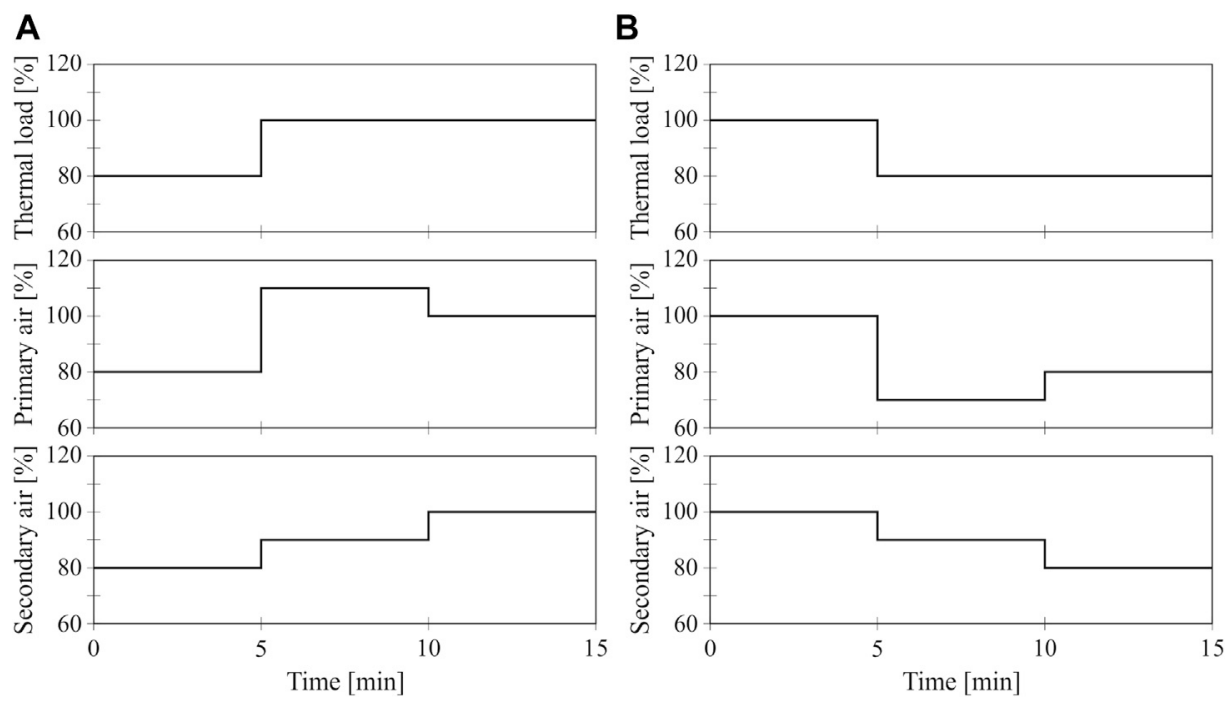

FIGURE 12 | Concept of boosted hydrodynamics. (A) Load increase (B) Load decrease.
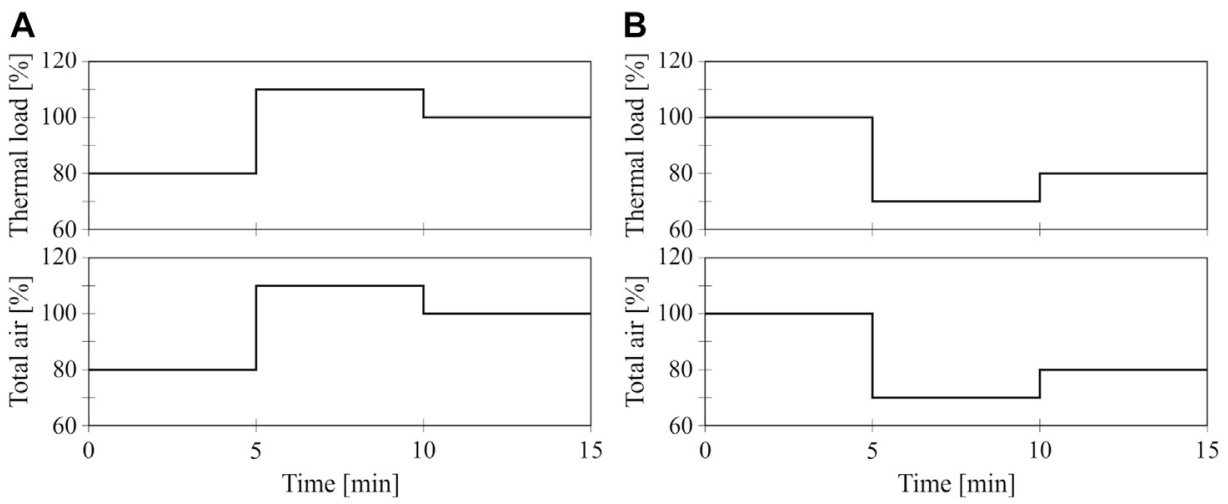

FIGURE 13 | Concept of elevated load steps. (A) Load increase (B) Load decrease.

above this setpoint to boost the entrainment and thereby the heat transfer coefficient. The secondary air must be increased below the setpoint to avoid negative effects such as cooling of the bed material by the increased excess air. After some minutes, both primary and secondary air are adjusted to the normal setpoint value. It is possible to use this concept for load reductions, by reducing the primary air below the targeted setpoint to reduce the entrainment (see Figure 12B). This concept has been successfully tested in pilot scale in the RFCS project Flex Flores (grant agreement n. 754032).

The experiments have shown that there is a positive effect of elevated load steps on the characteristic load ramps of the cooling system inside the furnace. This effect can be used by temporarily increasing (or decreasing) the thermal load above (or below) the new load level, see Figure 13.

The variation of the excess air factor during the load changes showed partly inconclusive results and the potential impact must be investigated further. However, despite this missing knowledge about the effect, a concept has been developed to use the dependence of the furnace temperature on the excess air factor to accelerate load ramps. During load increases, the combustion air is temporarily increased below the targeted setpoint to carry out the load change with a decreased excess air factor for a higher/ faster temperature increase, see Figure 14. The concept can be used vice-versa for load reductions. It is recommended to follow this strategy by controlling the secondary air in order not to negatively influence the entrainment by a reduced or increased primary air.

According to the experimental results, the concept of boosted hydrodynamics seems to be the most promising concept followed by the concept of elevated load steps. However, it might be most successful to have a combination of different concepts to accelerate load changes. The operating mode becomes more complicated with each concept so that automatic control systems will be crucial to keep control of all operational parameters. 

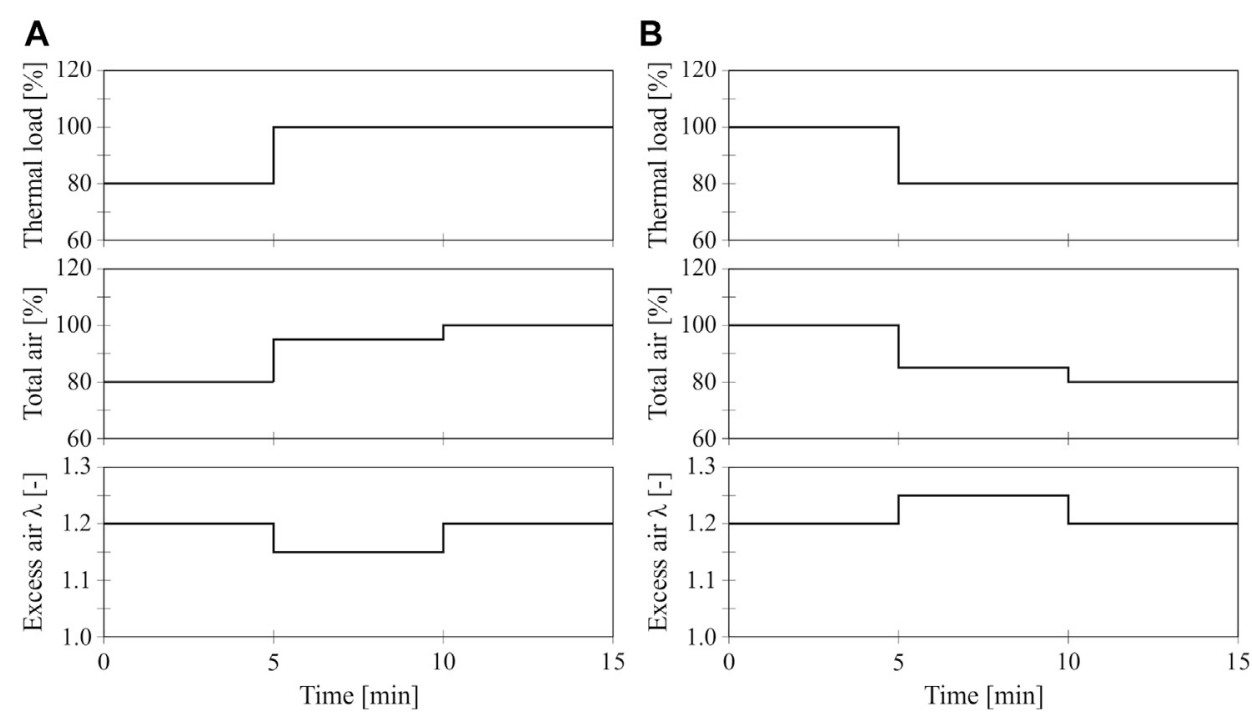

FIGURE 14 | Utilization of the excess air factor effect. (A) Load increase (B) Load decrease.

\section{CONCLUSION}

Dynamic test series with three different fuel mixtures were carried out in a $1 \mathrm{MW}_{\text {th }} \mathrm{CFB}$ combustor to investigate the influence of operational parameters on the load ramps. The most important parameters that have a significant influence on the load ramp were determined.

- The response of the waterside to a step input on the fireside of the CFB furnace is driven by the change of the hydrodynamic conditions and the furnace temperature.

- The primary air has a large impact on the entrainment of bed particles. A larger step input of the primary air causes a faster load change on the waterside.

- Load ramps on the cold side are faster with an increasing step size of the fuel mass flow. The fuel mass flow has a lower impact than the primary air.

- The results indicate that the overall load change behavior can only be explained by investigating at least three important step input parameters: primary air, thermal load, and excess air factor.

- The type of fuel mixture has an impact on the heat transfer coefficient due to different temperature levels, but the load ramps are not affected.

- Concepts were elaborated for the acceleration of load ramps by controlling the fireside conditions during the load changes.

The proposed concepts must be investigated further to assess their effectiveness on load ramp acceleration. Moreover, dynamic process simulations might be useful to test these and other concepts or a combination of several concepts before they can be applied to industrial-scale power plants.

\section{DATA AVAILABILITY STATEMENT}

The raw data supporting the conclusions of this article will be made available by the authors, without undue reservation.

\section{AUTHOR CONTRIBUTIONS}

Conceptualization by JP, JS, and BE. Methodology by JP and JS. Experimental investigation by JP and EL. Resources by JS and BE. Writing original draft by JP. Review and editing by JP, EL, and JS. Visualization of data by JP. Supervision by JS and BE. Project administration by JP, JS, and BE. Funding acquisition by JS and BE. All authors have read and approved the submitted version of the manuscript.

\section{FUNDING}

Financial support is acknowledged from the RFCS project of the European Commission under grant agreement n. 754032 (FLEXible operation of FB plants co-Firing LOw rank coal with renewable fuels compensating vRES- FLEX FLORES).

\section{ACKNOWLEDGMENTS}

The authors gratefully acknowledge fruitful collaboration with the project partners. We acknowledge support by the Deutsche Forschungsgemeinschaft (DFG-German Research Foundation) and the Open Access Publishing Fund of Technical University of Darmstadt. 


\section{REFERENCES}

Al-Mansour, F., and Zuwala, J. (2010). An Evaluation of Biomass Co-firing in Europe. Biomass and Bioenergy 34, 620-629. doi:10.1016/j.biombioe.2010.01.004

Alobaid, F., Peters, J., Amro, R., and Epple, B. (2020). Dynamic Process Simulation for Polish lignite Combustion in a 1 MWth Circulating Fluidized Bed during Load Changes. Appl. Energ. 278, 115662. doi:10.1016/j.apenergy.2020.115662

Arias, B. (2016). An Analysis of the Operation of a Flexible Oxy-Fired CFB Power Plant Integrated with a thermal Energy Storage System. Int. J. Greenhouse Gas Control. 45, 172-180. doi:10.1016/j.ijggc.2015.12.007

Basu, P., Butler, J., and Leon, M. A. (2011). Biomass Co-firing Options on the Emission Reduction and Electricity Generation Costs in Coal-Fired Power Plants. Renew. Energ. 36, 282-288. doi:10.1016/j.renene.2010.06.039

Beiron, J., Montañés, R. M., Normann, F., and Johnsson, F. (2019). Dynamic Modeling for Assessment of Steam Cycle Operation in Waste-Fired Combined Heat and Power Plants. Energ. Convers. Manag. 198, 111926. doi:10.1016/j. enconman.2019.111926

Biyikli, S., Tuzla, K., and Chen, J. C. (1987). Freeboard Heat Transfer in HighTemperature Fluidized Beds. Powder Technol. 53, 187-194. doi:10.1016/0032 5910(87)80093-1

Breitholtz, C., Leckner, B., and Baskakov, A. P. (2001). Wall Average Heat Transfer in CFB Boilers. Powder Tech. 120, 41-48. doi:10.1016/s0032-5910(01)00345-x

Cormos, C.-C. (2012). Integrated Assessment of IGCC Power Generation Technology with Carbon Capture and Storage (CCS). Energy 42, 434-445. doi:10.1016/j.energy.2012.03.025

Descamps, C., Bouallou, C., and Kanniche, M. (2008). Efficiency of an Integrated Gasification Combined Cycle (IGCC) Power Plant Including CO2 Removal. Energy 33, 874-881. doi:10.1016/j.energy.2007.07.013

Dutta, A., and Basu, P. (2004). An Improved Cluster-Renewal Model for the Estimation of Heat Transfer Coefficients on the Furnace walls of Commercial Circulating Fluidized Bed Boilers. J. Heat Transfer 126, 1040-1043. doi:10.1115/1.1833360

Edenhofer, O., Pichs-Madruga, R., Sokona, Y., Seyboth, K., Kadner, S., Zwickel, T., et al. (2011). Renewable Energy Sources and Climate Change Mitigation: Special Report of the Intergovernmental Panel on Climate Change. New York, NY, USA: Cambridge University Press

Gao, M., Hong, F., and Liu, J. (2017). Investigation on Energy Storage and Quick Load Change Control of Subcritical Circulating Fluidized Bed Boiler Units. Appl. Energ. 185, 463-471. doi:10.1016/j.apenergy.2016.10.140

Gnielinski, V. (1995). Ein neues Berechnungsverfahren für die Wärmeübertragung im Übergangsbereich zwischen laminarer und turbulenter Rohrströmung. Forsch Ing-Wes 61, 240-248. doi:10.1007/bf02607964

Grace, J. R., Knowlton, T., and Avidan, A. (1997). Circulating Fluidized Beds. London, UK: Blackie Academic and Professional.

Haaf, M., Peters, J., Hilz, J., Unger, A., Ströhle, J., and Epple, B. (2020). Combustion of Solid Recovered Fuels within the Calcium Looping Process - Experimental Demonstration at $1 \mathrm{MW}$ th Scale. Exp. Therm. Fluid Sci. 113, 110023. doi:10. 1016/j.expthermflusci.2019.110023

Hansson, J., Berndes, G., Johnsson, F., and Kjärstad, J. (2009). Co-firing Biomass with Coal for Electricity Generation-An Assessment of the Potential in EU27. Energy Policy 37, 1444-1455. doi:10.1016/j.enpol.2008.12.007

Heinze, C., May, J., Peters, J., Ströhle, J., and Epple, B. (2018). Environmental and Techno-Economic Assessment of Co-generation of Power and Fuels Based on Fluidized Bed Gasification. Proceedings of Challenges for Petrochemicals and Fuels: Integration of Value Chains and Energy Transition DGMK Conference. Berlin, Germany, 83-91.

Heinze, C., May, J., Peters, J., Ströhle, J., and Epple, B. (2019). Techno-economic Assessment of Polygeneration Based on Fluidized Bed Gasification. Fuel 250, 285-291. doi:10.1016/j.fuel.2019.04.020

Helbig, M., Hilz, J., Haaf, M., Daikeler, A., Ströhle, J., and Epple, B. (2017). Longterm Carbonate Looping Testing in a 1 MWth Pilot Plant with Hard Coal and lignite. Energ. Proced. 114, 179-190. doi:10.1016/j.egypro.2017.03.1160

Henderson, C. (2014). Increasing the Flexibility of Coal-Fired Power Plants. London, UK: IEA Clean Coal Centre.

Hilz, J., Haaf, M., Helbig, M., Lindqvist, N., Ströhle, J., and Epple, B. (2019). Scaleup of the Carbonate Looping Process to a 20 MWth Pilot Plant Based on LongTerm Pilot Tests. Int. J. Greenhouse Gas Control. 88, 332-341. doi:10.1016/j. ijggc.2019.04.026
Jäntti, T., Nuortimo, K., Ruuskanen, M., Kalenius, J., and Oy, F. W. E. (2012). Proceedings of PowerGen Europe. Cologne, Germany, 12-14. Samcheok Green Power 4 X 550 MWe Supercritical Circulating Fluidized-Bed Steam Generators in South Korea

Khavidak, S. S., Pallarès, D., Normann, F., Johnsson, F., and Ylä-Outinen, V. (2015). Heat Transfer in a 4-MWth Circulating Fluidized Bed Furnace Operated under Oxy-Fired and Air-Fired Conditions: Modeling and Measurements. Int. J. Greenhouse Gas Control. 37, 264-273.

Liu, Z., Ma, S., Pan, X., and Chen, J. (2019). Experimental Study on the Load Response Rate under the Dynamic Combined Combustion of PC Coal and CFB Coal in a CFB Boiler. Fuel 236, 445-451. doi:10.1016/j.fuel.2018. 07.091

Lockwood, T. (2013). Techno-economic Analysis of PC versus CFB Combustion Technology. London, UK: IEA Clean Coal Centre, Report CCC/226.

Lyu, J., Yang, H., Ling, W., Nie, L., Yue, G., Li, R., et al. (2019). Development of a Supercritical and an Ultra-supercritical Circulating Fluidized Bed Boiler. Front. Energ. 13, 114-119. doi:10.1007/s11708-017-0512-4

Majanne, Y., Yli-Fossi, T., Korpela, T., Nurmoranta, M., and Kortela, J. (2017). Utilization of Drum Boilers' Storage Capacity for Flexible Operation. IFACPapersOnLine 50, 2005-2010. doi:10.1016/j.ifacol.2017.08.186

Mills, S. J. (2011). Integrating Intermittent Renewable Energy Technologies with Coal-Fired Power Plant. London, UK: IEA Clean Coal Centre.

Molerus, O., and Mattmann, W. (1992). Heat Transfer Mechanisms in Gas Fluidized Beds. Part 3: Heat Transfer in Circulating Fluidized Beds. Chem. Eng. Technol. 15, 291-294. doi:10.1002/ceat.270150502

Molerus, O., and Wirth, K.-E. (1997). Heat Transfer in Fluidized Beds. London, UK: Chapman \& Hall. doi:10.1007/978-94-011-5842-8

Ohlemüller, P., Alobaid, F., Abad, A., Adanez, J., Ströhle, J., and Epple, B. (2018). Development and Validation of a 1D Process Model with Autothermal Operation of a $1 \mathrm{MW}$ Th Chemical Looping Pilot Plant. Int. J. Greenhouse Gas Control. 73, 29-41. doi:10.1016/j.ijggc.2018.03.013

Ohlemüller, P., Ströhle, J., and Epple, B. (2017). Chemical Looping Combustion of Hard Coal and Torrefied Biomass in a $1 \mathrm{MW}$ Th Pilot Plant. Int. J. Greenhouse Gas Control. 65, 149-159. doi:10.1016/j.ijggc.2017.08.013

Oka, S. (2003). Fluidized Bed Combustion. New York, NY, USA: Marcel Dekker. doi:10.1201/9781420028454

Paraschiv, F., Erni, D., and Pietsch, R. (2014). The Impact of Renewable Energies on EEX Day-Ahead Electricity Prices. Energy Policy 73, 196-210. doi:10.1016/j. enpol.2014.05.004

Park, C. K., and Basu, P. (1997). A Model for Prediction of Transient Response to the Change of Fuel Feed Rate to a Circulating Fluidized Bed Boiler Furnace. Chem. Eng. Sci. 52, 3499-3509. doi:10.1016/s0009-2509(97)00128-0

Peters, J., Alobaid, F., and Epple, B. (2020). Operational Flexibility of a CFB Furnace during Fast Load Change-Experimental Measurements and Dynamic Model. Appl. Sci. 10, 5972. doi:10.3390/app10175972

Peters, J., May, J., Ströhle, J., and Epple, B. (2020). Flexibility of CFB Combustion: An Investigation of Co-combustion with Biomass and RDF at Part Load in Pilot Scale. Energies 13, 4665. doi:10.3390/en13184665

Renewables, R. E. N21. (2019). Global Status Report. Paris, France: REN21 Secretariat.2019

Sami, M., Annamalai, K., and Wooldridge, M. (2001). Co-firing of Coal and Biomass Fuel Blends. Prog. Energ. Combustion Sci. 27, 171-214. doi:10.1016/ s0360-1285(00)00020-4

Stefanitsis, D., Nesiadis, A., Koutita, K., Nikolopoulos, A., Nikolopoulos, N., Peters, J., et al. (2020). Simulation of a CFB Boiler Integrated with a thermal Energy Storage System during Transient Operation. Front. Energ. Res. 8, 169. doi:10. 3389/fenrg.2020.00169

Ströhle, J., Hilz, J., and Epple, B. (2020). Performance of the Carbonator and Calciner during Long-Term Carbonate Looping Tests in a $1 \mathrm{MWth}$ Pilot Plant. J. Environ. Chem. Eng. 8, 103578. doi:10.1016/j.jece.2019.103578

Ströhle, J., Orth, M., and Epple, B. (2015). Chemical Looping Combustion of Hard Coal in a 1 MWth Pilot Plant Using Ilmenite as Oxygen Carrier. Appl. Energ. 157, 288-294. doi:10.1016/j.apenergy.2015.06.035

Ströhle, J., Orth, M., and Epple, B. (2014). Design and Operation of a 1 MWth Chemical Looping Plant. Appl. Energ. 113, 1490-1495. doi:10.1016/j.apenergy. 2013.09.008

Tourunen, A. S., Saastamoinen, J. J., Hämäläinen, J. P., Paakkinen, K. M., Hyppänen, T. E., and Kettunen, A. M. (2003). Study of Operation of a Pilot 
CFB-Reactor in Dynamic Conditions. Proceedings of 17th International Conference on Fluidized Bed Combustion. Florida, USA: Jacksonville, 353-361.

Walter, H., and Epple, B. (2017). Numerical Simulation of Power Plants and Firing Systems. Wien, Austria: Springer.

Werther, J. (2009). Potentials of Biomass Co-combustion in Coal-Fired Boilers. Proceedings of 20th International Conference on Fluidized Bed Combustion. Xi'an China, Berlin, Heidelberg: Springer-Verlag 27-42.

Wirth, K.-E. (1995). Heat Transfer in Circulating Fluidized Beds. Chem. Eng. Sci. 50, 2137-2151. doi:10.1016/0009-2509(95)00025-Z

Wu, R. L., Lim, C. J., Chaouki, J., and Grace, J. R. (1987). Heat Transfer from a Circulating Fluidized Bed to Membrane Waterwall Surfaces. Aiche J. 33, 1888-1893. doi:10.1002/aic.690331116

Yates, J. G., and Lettieri, P. (2016). Fluidized-bed Reactors: Processes and Operating Conditions. Basel, Switzerland: Springer International Publishing. doi:10.1007/ 978-3-319-39593-7
Zheng, L., Weidou, N., Guangxi, Y., Xin, S., and Wei, Z. (1997). Proceedings of 14th International Conference on Fluidized Bed Combustion. Vancouver: Canada, 11-14.A General Mathematical Model for the Total Ash Mass Balance of CFBC.

Conflict of Interest: The authors declare that the research was conducted in the absence of any commercial or financial relationships that could be construed as a potential conflict of interest.

Copyright (c) 2021 Peters, Langner, Ströhle and Epple. This is an open-access article distributed under the terms of the Creative Commons Attribution License (CC BY). The use, distribution or reproduction in other forums is permitted, provided the original author(s) and the copyright owner(s) are credited and that the original publication in this journal is cited, in accordance with accepted academic practice. No use, distribution or reproduction is permitted which does not comply with these terms. 